\title{
University of Arizona-Phoenix Receives Full Accreditation
}

University of Arizona (UA) officials announced yesterday that the UA College of Medicine-Phoenix, which was originally a branch of the UA-Tucson medical school, was granted full accreditation by the Liaison Committee on Medical Education (LCME) (1). The College of Medicine-Phoenix was created 10 years ago. In 2012, the UA College of Medicine-Phoenix received "preliminary" accreditation with the LCME, then "provisional" accreditation in 2015 and now full accreditation.

To date, the UA College of Medicine-Phoenix has graduated 354 physicians, with classes of about 80 students per year. One year ago this month, the Arizona Medical Association asked for an investigation after a half-dozen of the Phoenix medical school's top leaders left for positions out of state. Among those departures was the school's dean, Dr. Stuart D. Flynn. Dr. Kenneth Ramos served as interim dean and helped lead the Phoenix medical school through the accreditation. Dr. Guy Reed from Tennessee was recently hired as the school's new dean and assumes his duties in July.

There are now five medical schools in Arizona: the two UA medical schools; the Mayo Clinic School of Medicine, which is opening its Arizona campus in Scottsdale this summer; and Midwestern University and A.T. Still University, which both operate osteopathic medical schools in the Phoenix area. A sixth medical school, Omaha-based Creighton University School of Medicine, has medical students doing third- and fourth-year rotations in Arizona.

Richard A. Robbins, MD

Editor, SWJPCC

\section{Reference}

1. Innes S. University of Arizona's Phoenix medical school receives full accreditation. Arizona Star. June 14, 2017. Available at:

http://tucson.com/news/local/education/college/university-of-arizona-sphoenix-medical-school-receives-full-accreditation/article 64a1da80-18665a51-a062-7cc04ecd261d.html (accessed 6/15/17). 